\title{
Contos da Infância e do Lar: da Tradição Oral à Literatura para a Infância'
}

Children's and Household Tales: from Oral Tradition to Children's Literature

\author{
CARLAALEXANDRA GUERREIRO \\ Instituto Politécnico de Bragança \\ Portugal \\ carlaguerreiro.ese@gmail.com
} (Recibido o8-OI-2OI3;
aceptado I2-O8-20I3)

Resumo. Os irmãos Grimm (Alemanha- séc.XIX) foram dos mais prolíferos escritores de histórias de potencial receção Infanto-juvenil, tornando imortais contos como: "Capuchinho Vermelho", "A cabra e os sete cabritinhos", “A bela Adormecida” ou "Gata Borralheira”, entre outros, que continuam no século XXI a despertar sonho e magia nas mentes infantis.

No nosso artigo, trataremos de refletir sobre a originalidade e importância da sua obra literária: Contos da infância e do lar, revisitando os aspetos mais importantes e significativos nela enunciados. Para isso, seguimos uma metodologia analítica, baseada nos textos originais dos Grimm, bem como em especialistas atualizados nesta matéria.

Palavras-Chave: Contos tradicionais; literatura infantil; Irmãos Grimm; contos da infância e do lar.

Abstract. The Brothers Grimm (Germany-XIXth century) were the most prolific writers of stories intended for the young public. They were so popular that stories such as 'Little Red Riding Hood', 'The Wolf and the Seven Young Goats', 'Sleeping Beauty' or' Cinderella', among others, still continue to produce the dream and the magic on the minds of the children of the XXI century.

Our work reflects on the importance and originality of their literary work: Children's and Household Tales, revising the most meaningful and important features within it. We follow an analytical methodology based upon the original texts by the Brothers Grimm and upon the use of experts on this field.

Keywords:Traditional folk tales; children's literature; Brothers Grimm; children's and household tales.

Resumen. Los Hermanos Grimm (Alemania-XIX) fueron los más prolíficos escritores de historias de potencial acogida infantil y juvenil, convirtiendo en inmortales, cuentos como: "Caperucita Roja”, “La Cabra y las siete cabritillas”, “La Bella Durmiente” o “Cenicienta”, entre otras, que siguen despertando el sueño y la magia en la mente de los niños del siglo XXI.

En nuestro artículo, se reflexiona sobre la importancia y la originalidad de su obra literaria: Cuentos de la infancia y el hogar, revisando los aspectos más importantes y significativos contenidos en ella. Seguimos una metodología analítica, basada en los textos originales de los hermanos Grimm, así como el uso de expertos en este campo.

Palabras clave: Cuentos tradicionales; literatura infantil; Hermanos Grimm; cuentos de la infancia y el hogar.

\footnotetext{
I Para citar este artículo: Guerreiro, Carla Alexandra (20I3). Contos da Infância e do Lar: da Tradição Oral à Literatura para a Infância. Alabe 8. [www.revistaalabe.com]
} 


\title{
I - Kinder und Hausmarchen-um tesouro literário nascido na Alemanha
}

Os Contos da Infância e do Lar "Kinder- und Hausmärchen" coletânea da célebre coleção de histórias de Jacob e Wilhelm Grimm, cuja I. ${ }^{\mathrm{a}}$ publicação foi em I8I2, mudou o rumo da literatura, estando traduzida em mais de I5o línguas e contribuindo significativamente, na atualidade, para o modo como produzimos fantasia.

Jacob e Wilhelm Grimm dedicaram mais de uma década à investigação sobre o folclore alemão. Tal pesquisa possibilitou que eles coligissem centenas de contos que vinham sendo contados e recontados verbalmente desde a Idade Média, deixando-nos um valioso legado, conhecido como "Os Contos de Grimm".

Os Contos da Infância e do Lar, dos irmãos Grimm, são a obra de língua alemã mais traduzida e editada no mundo, crescendo em popularidade ao longo do século XIX e consagrando-se como um dos tesouros da cultura popular alemã e europeia. Os ideais de rigor e de fidelidade por que se regia e os valores nacionalistas em que assentava inspiraram projetos idênticos de recolha de contos orais um pouco por toda a Europa (lembremos, a título de exemplo, os portugueses Adolfo Coelho ou Teófilo Braga). A particularidade, no caso dos Irmãos Grimm, é que eles não só recolheram os contos como lhes deram o seu toque pessoal. Nas palavras de Calvino:

\begin{abstract}
Nunca se lhes perde de vista o espírito "nacional-popular" que animava o seu trabalho de estudiosos (espírito típico da época em que em vários países da Europa se formava e difundia uma consciência patriótica, e sobretudo típico da geração alemã que tinha vinte anos quando a Alemanha foi ocupada pelos exércitos napoleónicos): para os Grimm o compromisso patriótico exprimia-se na metódica redescoberta da literatura da remota antiguidade germânica e de tudo o que antes da escrita ocupara o lugar da literatura: cantos populares, provérbios, contos transmitidos de boca em boca (Calvino,r999:77).
\end{abstract}

Os Grimm não foram os primeiros a subscrever o ideário romântico, nem este tão pouco se confinava ao espaço da língua alemã. Também tiveram alguns percursores ao nível da pesquisa e da recolha de tradições populares. O que os distinguiu foi o volume e a qualidade do seu trabalho, o rigor e seriedade que o caraterizaram e o impacto que teve entre os seus contemporâneos e as gerações subsequentes por toda a Europa ${ }^{2}$.

Os Contos da Infância e do Lar constituem apenas uma pequena parte de uma obra extremamente prolífera. Para além dos oito livros que escreveram em conjunto, Jacob Grimm é autor individual de vinte e um livros e o seu irmão Wilhelm de catorze, sem contar com um espólio enorme que inclui doze volumes de ensaios e notas e uma correspondência de milhares de cartas. Os seus estudos e recolhas de literatura tradicional inserem-se numa linha mais vasta de interesses que abrangem a literatura alemã antiga e

\footnotetext{
${ }^{2}$ Com efeito, tomando por modelo os Contos da Infância e do Lar, realizaram-se ainda no século XIX importantes recolhas de contos populares na Rússia, Suécia, Roménia, Itália, Inglaterra, Escócia, Inglaterra, entre outros países.
} 
comparada, a lexicografia, a linguística histórica e comparada, a mitologia germânica e europeia, a jurisprudência, a etnografia e a religião.

Os contos recolhidos pelos Grimm passavam oralmente das mães aos filhos, ninguém sabia há quantas gerações, sem jamais terem tido as formas das suas histórias fixadas pela escrita. Assim, uma família de, digamos, lenhadores ou carvoeiros que vivesse há séculos nas densas florestas alemãs poderia relatá-las de modo bem diferente de uma outra família que houvesse sempre vivido em re $\neg$ giões de céu aberto ou nas fazendas dos vales.

Jacob e Wilhelm tinham ouvido com frequência esses contos na infância, mas agora examinavam-nos com outros olhos, olhos críticos, e com a esperança de que eles iluminassem a história, as crenças e os costumes da longa sucessão de camponeses alemães que tinham concedido a essas histórias as suas formas finais. Os irmãos va $\neg$ lo $\neg$ rizavam os relatos, devido ao seu material folclórico, sendo, portanto, essencial que fossem obtidas tantas versões de cada história quantas as possíveis, e que cada uma fosse registrada com absoluta fidelidade à narrativa feita pelos camponeses nas suas choupanas. Os escritores declararam, aquando da publicação dos contos, não ter embelezado nenhum dos seus eventos ou traços caraterísticos, sublinhando que cada história era recontada substancialmente $c 0 \neg$ mo a tinham recebido.

\section{I.I. Fontes da recolha literária dos irmãos Grimm}

Os Grimm encarregaram algumas pessoas de confiança de irem às casas dos camponeses recolher as histórias das mulheres mais idosas. Estes assistentes ouviam a mesma história vezes sem conta, até as terem em todas as suas riquezas de dialetos e detalhes, mas uma parte significativa das histórias recolhidas, teve como fonte o seu círculo de amizades em Kessel, que incluía as famílias Von Haxthausen e Hassenplufge as irmãs Jenny e Annette Von Droste-Hülsholff. Isto significa que os Grimm obtiveram uma importante parte do seu material junto de uma classe burguesa e aristocrática, educada e profundamente familiarizada com a cultura francesa.

Então os irmãos trabalhavam nos relatos com a precisão e o método caraterísticos do seu povo, colhendo uma frase aqui, uma palavra ali, como testemunhos de lendas e mitos esquecidos. Para eles, os gnomos, as fadas, os gi gantes, os duendes das minas e os duendes ami $\neg$ gos dos homens eram parte de um passado esquecido. A bacia de leite posta junto às brasas da lareira, à noite, pelas donas de casa para agradar aos duendes amigos indicava, aos olhos desses filólogos, um elo direto com os sacrifícios oferecidos antigamente aos deuses nos altares. Os irmãos “aprenderam" que um gigante podia, aparentemente, ser tão velho quanto as montanhas, embora um anão já fosse um adulto aos três anos de idade e um velhote, aos sete. "Descobriram” que algumas crianças saudáveis eram substituídas nos seus berços pelas crias das fadas para que estas últimas melhorassem os seus corpos franzinos e que os buracos dos nós das madeiras eram portas pelas quais os duen $\neg$ des e as fadas se infiltravam nas habitações humanas, jun $\neg$ tamente com os raios de sol. 
Contudo, nem todo o material foi recolhido via oral, algum foi extraído de manuscritos medievais, folhetos populares e textos religiosos do tempo de Lutero. Mas sobretudo há que dizê-lo, os Grimm, especialmente Wilhelm, entendiam a sua fidelidade mais no espírito do que na letra: traduziam (dos dialetos) e recontavam as histórias com base numa sua ideia de simplicidade popular. Por exemplo, conhecemos três reedições sucessivas da "Branca de Neve" porque de edição para edição, o texto sofria retoques. Na verdade, os Grimm, com os anos, foram mudando de ideias quanto à exatidão científica na reprodução da narração oral: enquanto primeiro, o seu ponto de honra era registar a história que ouviam palavra por palavra e, por vezes, as variantes de uma história contada por narradores diferentes, a seguir convenceram-se de que o seu dever era reconstituir com base nas variantes o texto mais provável da história original. Aliás esta preocupação com a autenticidade era partilhada pelos Grimm, que ao longo das sucessivas reedições da coleção foram eliminando contos que concluíram serem importações de material estrangeiro ou de origem germânica incerta, tal como faziam notar nas suas notas aos contos.

Em I8I5, os irmãos Grimm produziram o segundo volume dos Contos da Infância e do Lar, reimpresso de forma aumentada em I8I9. As notas sobre os contos dos dois volumes foram publicadas em I822. Uma nova edição que condensava os outros três volumes num único surge em I825 e contribui grandemente para a sua popularidade. Essa edição foi ilustrada pelo irmão dos autores, Ludwig Emil Grimm. A partir de I823 apareceu uma edição inglesa ilustrada dos Contos.

A tese dos Grimm era que os contos de fadas derivavam dos grandes temas épicos da mitologia germânica, como a saga dos Nibelungos. O folclore-estudo das tradições étnicas era uma ciência que estava a nascer e o livro dos Grimm abria caminho a um ramo desta ciência, a novelística popular comparada.

Durante a vida dos dois irmãos apareceram sete impressões da edição completa em três volumes dos contos e dez da edição reduzida a um volume único. A quinquagésima edição, última com os autores vivos, já totalizava I8I narrativas. Algumas dessas histórias são de fundo europeu comum, tendo sido também recolhidas por Charles Perrault, no século XVII, em França, o que remete para existência de uma fonte comum³

\section{2 - Algumas propostas para a compreensão da(s) mensagem(s) dos Contos}

Originalmente, as histórias não tinham nenhum apelo infantil, muito pelo contrário. Violentas e com valores questionáveis, tais estórias contadas em tavernas e entre os viajantes, eram ricas em elementos folclóricos, personagens fascinantes e cenários fantásticos. Na tradição oral, as histórias compiladas não eram destinadas ao público infantil e sim aos adultos, começando por ser um trabalho de recolha etnográfica. A intenção ori-

\footnotetext{
3 A preocupação com a autenticidade era particularmente tida em conta pelos Grimm, que ao longo das sucessivas reedições da coleção foram eliminando contos que concluíram serem importações de material estrangeiro ou de origem germânica incerta, tal como faziam notar nas suas notas aos contos.
} 
ginal deste livro não era, de modo nenhum, fazer dele um livro de histórias para crianças, pelo que não era necessário nem desejável expurgar conteúdos impróprios para crianças. Assim, a edição de I8ı2 continha elementos que outros colecionadores de contos puseram em causa, apontando a falta de gosto e o caráter pouco refinado de algumas passagens. Os Grimm não ficaram indiferentes a estas críticas. Wilhelm, em particular, introduziu sucessivas alterações aos textos a fim de adequar a coleção ao público burguês. Desta forma, muitos contos da última edição em vida dos autores divergem significativamente das versões publicadas em ı9ı2. Mas o objetivo dos Grimm foi também o de captarem aquilo que consideravam ser a verdadeira essência poética dos textos.

As alterações que os irmãos foram fazendo aos contos, associadas ao facto de a partir de I8I9 a maior parte dos contos incluídos na coleção provir de fontes literárias escritas levam a que não possamos entender os Grimm como apenas guardiães da literatura oral, mas também como seus recriadores ativos. Do que não há dúvidas é que, sem eles, histórias que hoje qualquer criança conhece, de uma forma ou de outra, estariam provavelmente perdidas, nunca teriam chegado até nós. Foram os irmãos Grimm que as dedicaram às crianças pela sua temática mágica e maravilhosa. Fundiram, assim, esses dois universos: o popular e o infantil (o próprio título escolhido para a coletânea já evidencia uma proposta educativa).

Subscrevemos integralmente a posição de Traça (I992), quando afirma que, na maior parte dos contos, a satisfação dos desejos das personagens é um programa de sobrevivência e não uma simples evasão no imaginário, sendo as raízes no mundo real bem palpáveis. Os contos populares coletados pelos Grimm mostram pais que trabalham, enquanto os filhos apanham lenha, guardam animais, vão buscar água. As famílias camponesas só podiam sobreviver se todos os seus membros trabalhassem e longe de condenar-se o trabalho infantil, a indignação surge quando as tarefas não se realizam.

Nas histórias: "Rumpelstilskin", "O Rei barba-velha" e noutros contos, é ordenada a execução de tarefas de difícil ou mesmo impossível concretização da noite para o dia; elas exprimem, de uma forma hiperbólica a realidade duríssima da vida dos camponeses:

Em oposição ao mundo dos reis, o mundo dos camponeses. A orientação realista de muitos contos de fadas, o dado de partida de uma condição de extrema miséria, de fome, de falta de trabalho (...) Quem sabe como é raro na poesia popular (e não popular) construir um sonho sem se refugiar na evasão, apreciará estes extremos de uma autoconsciência que não rejeita a invenção de um destino, esta força de realidade que explode totalmente em fantasia. Melhor lição, poética e moral não poderiam dar-nos os contos de fadas (Calvino, I99:50-5I).

Podemos entrever, pois, nos contos populares uma forma de os camponeses enunciarem as suas aspirações e projetarem a possibilidade de um conjunto de meios imaginários que lhes permitissem metamorfosear a dura realidade das suas vidas, mas, ao mesmo tempo, apresentavam essa mesma realidade, sem esconder os aspetos mais violentos: crianças esfomeadas ("Hansel e Grettel”), castigos corporais ou mesmo tentativas 
de incesto ("Pele de Gato") e exploração intensiva ("A Luz Azul"), para não dar mais que alguns exemplos. Estas condições de vida, segundo Zipes (I979), eram tão terríveis que obrigavam a uma abstração simbólica e constituiriam as raízes do conto popular.

Com propósito académico, Jacob e Wilhelm, publicaram os Contos com 900 exemplares de tiragem, inicialmente. Posteriormente, estes foram repaginados e transcritos para uma linguagem mais infantil, porém, sem perder a sua essência mágica, as suas personagens e sem lhes ser retirado qualquer aspeto fantástico.

\section{3- O Romantismo e os Contos de Grimm}

O séc. XIX constitui-se como período de consolidação da Literatura para Crianças. Esta consolidação prende-se, a nosso ver, com o Romantismo que, pelas suas caraterísticas vai ter grande influência na produção da Literatura para a Infância: renovase o interesse pelo folclore que está na base das Literaturas Popular e Infantil e revitalizase o uso das fadas nos contos e romances.

Ao revogar a rigidez do Classicismo e as inflexibilidades morais e religiosas herdadas da Reforma e da Contra-Reforma, ao adoptar os ideais rousseauianos, como o símbolo do bom selvagem, o Romantismo cria as condições, até ao momento não reunidas, para o desenvolvimento da Literatura Infantil. Também as teorias pedagógicas que apontam para puerocentrismo (...) vão contribuir para que comece a existir uma literatura conscientemente infantil (Teixeira Araújo,2008:92).

Com efeito, a pedagogia nova, apostada numa educação não violenta, encontrou no Romantismo um excelente aliado, devido ao seu sentido humanitário. Isto reflete-se nas produções literárias escritas para crianças ou também para crianças.

Assim, a violência presente nos contos de Charles Perrault, cede lugar a um humanismo, onde se destaca o sentido do maravilhoso da vida. Perpassam pelas histórias dos Grimm, de forma suave, duas temáticas em especial: a solidariedade e o amor ao próximo. A despeito dos aspetos negativos que continuam presentes nessas histórias, o que predomina, sempre são a esperança e a confiança na vida. A este nível é significativo o final do conto "Capuchinho Vermelho", de Perrault, em comparação com o fim deste conto na versão dos Grimm: no primeiro, o lobo devora a menina e a avó, no segundo, o caçador abre a barriga da fera, deixando que as duas saiam e vivam felizes.

As diferenças entre as duas versões são várias e significativas e têm em conta a evolução do conceito e sentimento da Infância entre os sécs. XVII e XIX. A um conceito da Criança-brinquedo vai opor-se no séc. XIX o Racionalismo que vem do séc. das luzes (responsável pela noção da necessidade de dar às crianças uma educação de acordo com a religião e a moral) e o Romantismo (com toda a sua carga de fantasia e ingenuidade. É, pois a esta luz que devemos analisar as diferenças.

Ao contrário de Perrault, os Grimm não realçam a figura do lobo, que simboliza a violência e que facilmente pode ser conotada com a dureza das condições de vida que as 
crianças ainda tinham, mas a do Capuchinho, que simboliza a candura e nos remete para a ideia de doçura, projetando-se na conceção de Infância do séc. XIX.

Os irmãos Grimm dão duas versões desta história, o que é muito raro neles. Na variante somos informados de que, tempos depois, quando a Capuchinho Vermelho ia novamente levar bolos à avó, outro lobo tentou induzi-la a desviar-se do caminho direto (da virtude). Desta vez, a pequena apressa-se a chegar a casa da avó e conta-lhe o que se passou. Juntas trancam a porta, de forma a que o lobo não possa entrar. No fim, o lobo escorrega do telhado para um recetáculo de comida para animais cheio de água e morre afogado. A história acaba com a frase: "E o Capuchinho Vermelho voltou para casa muito contente e nunca mais lhe tornaram a fazer mal" (Grimm,2OI2:238).Esta variante corrobora aquilo de que o narratário da história está convencido- que, depois da sua desagradável experiência, a menina não está suficientemente amadurecida para lidar com o lobo (Perigo) e está pronta para entrar numa aliança eficaz com o adulto.

O sentimento da Infância no séc. XVII e no XIX está subjacente aos textos de Perrault e Grimm. Na versão do primeiro autor, a rapariguinha simples perde-se e nunca mais se vê. Já na versão dos segundos, ela é salva graças aos adultos responsáveis por ela.

\section{4-Temas recorrentes nos contos de Grimm}

A coleção de contos dos irmãos Grimm foi reeditada sete vezes durante as suas vidas, sempre revista e aumentada. Wilhelm, que terá sido o mais conservador dos irmãos, assegurou a maior parte das revisões, encarregando-se, desde a I ${ }^{\mathrm{a}}$ edição de os expurgar e tornar mais respeitáveis para os filhos das classes burguesas, embora a publicação original nunca tivesse sido expressamente dedicada às crianças, como já afirmámos, mas com a intenção de escrever um livro que desse prazer e saber.

A maior parte dos contos suscitam uma atenção consciente a valores e exemplos prescritos. Ao ouvirem ler ou lerem elas próprias, as crianças são confrontadas com determinados papéis, adquirem valores e normas. Concordamos com Traça (I992), quando afirma que a maior parte dos contos dos Grimm implica uma luta pelo poder e a autonomia. Como ser capaz de aprender a usar os seus poderes pessoais no sentido positivo, de forma a ser aceite na sociedade ou a recriar as suas normas, respeitando as regras do statu quo.

Na sua busca, o herói deixa, frequentemente, a casa paterna para ir construir outro lar. Mas encontram-se comportamentos diferentes ao longo desta demanda, conforme se trate de um protagonista masculino ou feminino. Se se trata do herói, o seu objetivo é o dinheiro, o poder e uma mulher, associada também à propriedade. A astúcia, o engenho e a competitividade que se vão ganhando ajudam-no a conquistar o mundo, onde dominará. Se se trata de uma heroína, o seu objetivo é a riqueza, as joias e um homem para proteger os seus direitos de propriedade. A passividade, o trabalho, a paciência e um certo gosto pelo sacrifício, ajudam-na a encontrar a sua felicidade, dependente da sua obediência às regras patriarcais, vindo a reinar no seu lar ou no seu castelo. As atitudes das heroínas nos 
contos "clássicos" são de tal forma restritas, que estas permanecem quase imobilizadas.

Os heróis partem à aventura, lutam com monstros, enfrentam terríveis gigantes; as heroínas são bem comportadas, não saem nunca dos caminhos conhecidos, isto quando não são fechadas em torres, palácios, jardins ou choupanas. Com efeito, elas estão escondidas, prisioneiras e adormecidas e, na maior parte dos casos, limitam-se a esperar.

Citando Traça:

Não viajam voluntariamente, são obrigadas a fugir ou são raptadas. Dir-se-ia que se limitam a pôr-se bonitas para se casarem, ter filhos e ocupar-se das tarefas domésticas. A nota dominante é a presença da mulher- amante, da mulher- esposa, da mulher- reprodutora, ou seja, reduzida ao âmbito do lar, do amor, da gestação. Os idealizados estereótipos femininos encarnados pelas Cinderelas, Brancas de Neve, Grisélidas e demais heroínas não se afastam deste critério (Traça, I992:97).

Desde muito cedo, a criança do sexo feminino aprende que para ser feliz é preciso esperar pelo amor. A mulher á a "Bela Adormecida no bosque", a "Pele de Gato", a "Cinderela" ou "Branca de Neve", a que recebe e a que sofre. A suprema necessidade para a mulher é cativar o coração masculino; mesmo quando é intrépida e aventureira, esta é sempre a recompensa a que aspira. Parafraseando Lieberman, milhões de mulheres devem certamente ter formado a sua auto-imagem psicossexual e as suas ideias daquilo que podiam ou não realizar, do tipo de comportamento que seria recompensado e da natureza da própria recompensa, em parte, a partir dos seus contos de fadas preferidos. Estas histórias têm-se tornado nos repositórios dos sonhos, esperanças e fantasias de gerações de raparigas.

Com efeito considera-se a possibilidade de os atributos clássicos da "feminilidade" encontrados nestas histórias serem de facto transmitidos às crianças e reforçados por elas, podendo mesmo considerarmos que a análise da literatura para crianças considerada mais "popular” poderia fornecer dados sobre as origens da identidade psicossexual.

O conto "de fadas" fornece um primeiro esquema, ainda que ingénuo, primário das relações do Homem com o Universo. O encantamento que proporciona está na descoberta do novo, desde que, no entanto, o novo seja à medida da criança, isto é que tenha pontos de referência com a sua experiência passada, que se preste a contrastes e comparações: é necessário o desconhecido, inserido no conhecido.

É assim que o maravilhoso deve ser: viagem em países extraordinários, exotismo, aventuras surpreendentes, encontro com personagens prodigiosas, em suma tudo o que é susceptível, segundo a idade da criança, de suscitar o seu espanto ou curiosidade ávida (Traça, op. cit.:IO3). 


\section{5 - Para uma tentativa de categorização dos contos de Grimm}

Os Contos de Grimm não são se limitam a ser "contos de fadas", distribuindo-se em:

I. Contos de encantamento (histórias que apresentam metamorfoses, ou transformações, a maioria por encantamento);

2. Contos maravilhosos (narrativas que apresentam o elemento mágico, sobrenatural, integrado naturalmente nas situações apresentadas);

3. Fábulas (histórias vividas por animais);

4. Lendas (ligadas ao princípio dos tempos ou da comunidade e onde o mágico aparece como "milagre" ligado a uma divindade); desvendado);

5. Contos de enigma ou mistério (que têm como eixo um enigma a ser

6. Contos jocosos (humorísticos ou divertidos).

Os anões e os gnomos são as personagens mais caraterísticas do mundo mágico germânico e da compilação dos Grimm. O "povo pequeno" é composto por presenças, geralmente, boas, como em "Branca de Neve", "O bosque dos duendes" ou "Os duendes e o sapateiro". No outro extremo, o "povo dos gigantes", em contrapartida, é ameaçador, mas simplório, de forma que "O pequeno alfaiate valente" consegue sempre ganhar-lhes. Mas as dimensões alteram-se facilmente e é um "Polegarzinho", " alimentado por comida de gigantes" que se havia transformado no gigante ameaçador.

Os temas de que falámos não devem fazer esquecer que este é também o livro da comicidade camponesa. Os contos são igualmente ricos em historietas alegres e o espírito jocoso popular está presente nas histórias dos espertos e dos parvos, tais como: "Hans e a sua Mulher Grettel" ou "Abibe".

Se tivéssemos de escolher qual é para nós a história mais bela dos Contos da Infância e do Lar e a mais completa de todas as que o compõem, diríamos que é: "A Lua" porque congrega o mito cosmogónico, a narrativa aldeã, a iconografia do Além cristão e a comicidade do absurdo.

A caraterística básica das narrativas dos Grimm (qualquer que seja o seu tipo de texto) é a de apresentar uma problemática simples, um só núcleo dramático. A repetição, ou reiteração, juntamente com a simplicidade de problemática e da estrutura narrativa, é outro elemento constitutivo básico dos contos populares. Da mesma forma que a simplicidade da mente popular, também a infantil, repudia as estruturas narrativas complexas (devido à dificuldade de compreensão imediata que elas apresentam), também se desinteressando da matéria literária que apresente excessiva variedade ou novidades que alterem continuamente as estruturas básicas já conhecidas.

Essa reiteração dos mesmos esquemas na literatura popular e na de potencial receção infantil vai, pois, ao encontro da exigência interior dos seus leitores: apreciarem a repetição de situações conhecidas porque isso permite o prazer de conhecer, por antecipação, tudo o que vai acontecer na história. E mais, dominando, a priori, a marcha dos 
acontecimentos, o leitor sente-se seguro interiormente. É como se pudesse dominar a vida que flui e lhe escapa.

A simbologia e a fantasia das diferentes passagens dos contos vão dando o alento e a tranquilidade de que (a criança) necessita para progredir na senda da vida porque (...) este tipo de literatura é sempre construtivo, edificante, pacífico (Santos, 20O2:II6).

\section{Conclusão}

As obras comuns mais significativas de Jacob e Wilhelm Grimm são: a sua compilação de contos, a recoleção de lendas, assim como o Dicionário de Língua alemã, que não chegou a ser terminado. Jacob Grimm trouxe contribuições de primeira importância para a linguística alemã então nascente, que ajudaram a fundar a gramática histórica e comparada.

Procurando encontrar as origens da realidade histórica do seu país, Jacob e Willelm encontraram o fantástico, o mítico, em temas comuns da época medieval. Com as suas pesquisas, perseguiram dois objetivos básicos: o levantamento de elementos linguísticos para a fundamentação dos estudos filológicos da língua alemã e a fixação dos textos do folclore literário germânico, expressão autêntica do espírito nacional.

Muitos motivos narrativos que aos Grimm pareceram tipicamente alemães reencontram-se em toda a europa, e não só, também no mundo islâmico e na Índia. Surgiu a disputa entre os defensores da "monogénese" (ou seja a origem de um mito ou conto ou de um costume num lugar e época precisos e a sua sucessiva irradiação) e da poligénese (ou seja, a sua origem simultânea em vários lugares, dada a natureza humana comum e um nível desenvolvimental mais ou menos homogéneo)

Foi na Finlândia que o trabalho dos Grimm encontrou os maiores continuadores, daí nascendo uma tradição de estudos a que se devem catalogações importantes de temas e de motivos fabulísticos, com base nos quais se pode tentar traçar o percurso de cada conto, através dos tempos e dos países.

\footnotetext{
Algumas Escolas interpretativas identificaram nos motivos dos contos de fadas as fases dos ritos de iniciação; outras reconheceram neles os símbolos dos sonhos; ou também foram reduzidos a fórmulas esquemáticas como operações lógico-matemáticas. O debate entre as várias escolas continua, e os contos de fadas, em toda a sua elementar simplicidade, permanecem uma das mais misteriosas expressões da cultura humana. E continua-se sempre a fazer referência à recolha dos Grimm, arquétipo de todas estas investigações (Calvino, op. cit.:I999).
}

Desde o início, os Grimm pensaram também nos Contos da Infância e do Lar como livro destinado às crianças. Desta forma, quando o primeiro volume saiu, no Natal de I8I2, a capa foi desenhada por um terceiro irmão, (Ludwig) aparecendo um anjo da guarda ao lado de um pequeno veado e da menina de "Irmãozinho e Irmãzinha”, conferin- 
do um cunho cristão às metamorfoses pagãs do texto. A própria dedicatória do texto era dedicada a Bettina pelo seu filhinho. "Assim que o leu, Goethe escreveu a Charlotte von Stein que este era um livro feito para tornar felizes as crianças" (Calvino, op. cit.:8o).

De facto foi logo enorme o sucesso da obra entre as leituras infantis das famílias alemãs. Recordemos que naquela época não se pode ainda falar de uma Literatura para a Infância de acordo com as caraterísticas que se foram definindo nas décadas seguintes, mas mal ganhou forma, a produção de livros infantis, os volumes dos Grimm tornaram-se fonte de inúmeras traduções e versões, em todas as línguas, podendo resumirmos, em jeito de conclusão que, de alguma forma, com os Grimm surge uma grande literatura de potencial receção infantil que, ainda na atualidade encanta crianças de todo o mundo. 


\section{Referencias}

-Araújo, Armindo António Teixeira (2008). A Emancipação da Literatura Infantil. Porto: Campo das Letras.

- Bettleheim, Bruno (1999). Psicanálise dos Contos de Fadas. Lisboa: Bertrand Editora.8ª Ed.

- Calvino, Italo (1996). Sobre o Conto de Fadas. Lisboa: Teorema.

- Grimm, Jacob e Wilhelm (2012). Contos da Infância e do Lar, vol.-I.Lisboa: Círculo de Leitores.

- Lieberman, Marcia K. (I986). Some day my Prince will come: female acculturation through the Fairy Tale, pp. 56-58 in Zipes, Jack (org.) Don't bet on the Prince. New York: Gower.

- Santos, ManuelBragança(2002). Amagiado contono desenvolvimentointegral dacriança,p.ır6, in Mesquita, Pedagogias do imaginário. Porto: Edições Asa.

- Silva, Francisco Vaz da (Coord.) (20I2). Irmãos Grimm.Contos da Infáncia e do Lar-Vol-I. Lisboa: Círculo de Leitores.

- Traça, Maria Emília (1998). O Fio da Memória, Do Conto Popular ao Conto para Crianças. Porto: Porto Editora.

-Zipes, Jack (1979). Breaking the magic Spell:Radical Theories of Folk and fairy Tales. New York: Methuen. 